\title{
Inductive Power Transfer System for an Excavator by considering Large Load Fluctuation
}

\author{
Keisuke Kusaka* Member, Kent Inoue* Non-member \\ Jun-ichi Itoh ${ }^{* a)}$ Senior Member
}

(Manuscript received June 13, 2018, revised Nov. 7, 2018)

\begin{abstract}
In this study, an inductive power transfer system (IPT) was designed and developed for an excavator, which will be operated under high air pressure. In the conventional excavator systems, power is supplied through trolley wires. The contact between the trolley wires and a pantagraph may be a reason of fire due to a spark because the excavator works under high air pressure. In the proposed system, a series resonance capacitor on a primary side and a parallel resonance capacitor in a secondary side is used to cancel out the leakage inductance. By using the series-parallel compensation, the load voltage is ideally constant regardless of load fluctuation. However, the constant-voltage characteristic may degrades when a winding resistance and an error of the resonant parameter cannot be ignored. Thus, the resonant parameters must be designed considering the error. This paper proposes the design method of the resonant parameter with the voltage ratio maps considering the error of the parameter including the winding resistance. The experimental results confirmed that the voltage fluctuation is smaller than $4.3 \%$ with a developed $15-\mathrm{kW}$ IPT system. Furthermore, the constant-voltage characteristic is maintained even when the output power of an induction motor changes from 5 to $15 \mathrm{~kW}$ and vice versa.
\end{abstract}

Keywords: inductive power transfer, excavator, series-parallel compensation, pneumatic caisson method

\section{Introduction}

Pressurized air is supplied into the working chamber for excavation in order to prevent underground water from coming into the chamber.

A pneumatic caisson method is used for many structures: foundations of bridges and buildings, shafts for insertion of shield tunneling machines, tunnel and railways ${ }^{(1)}$. Figure 1 outlines a schematic of the pneumatic caisson method. In the first process of the pneumatic caisson method, a reinforced caisson made of concrete is constructed on the ground. Then, an airtight working chamber is formed at the bottom of the caisson. Finally, the caisson is immersed in a water to a predetermined depth. At same time, the pressurized air is supplied into the working chamber from the ground by a compressor in order to prevent the underground water from coming into the chamber. Owing to the pressurized air, the working chamber environment is always under high air pressure.

Figure 2 illustrates the schematic of a charging system for the excavator, which is operated for the pneumatic caisson method. Figures 2(a) and (b) show the conventional power supply system and the proposed system, respectively. An excavator hangs onto the ceiling of the working chamber and moves along a traveling rail. Meanwhile, an electric hydraulic pump is used for the operation of the excavator. The power for an electric motor which drives hydraulic pump is supplied via trolley wires which are placed belong

a) Correspondence to: Jun-ichi Itoh. E-mail: itoh@vos.nagaokaut. ac.jp

* Nagaoka University of Technology

1603-1, Kamitomioka, Nagaoka, Niigata 940-2188, Japan

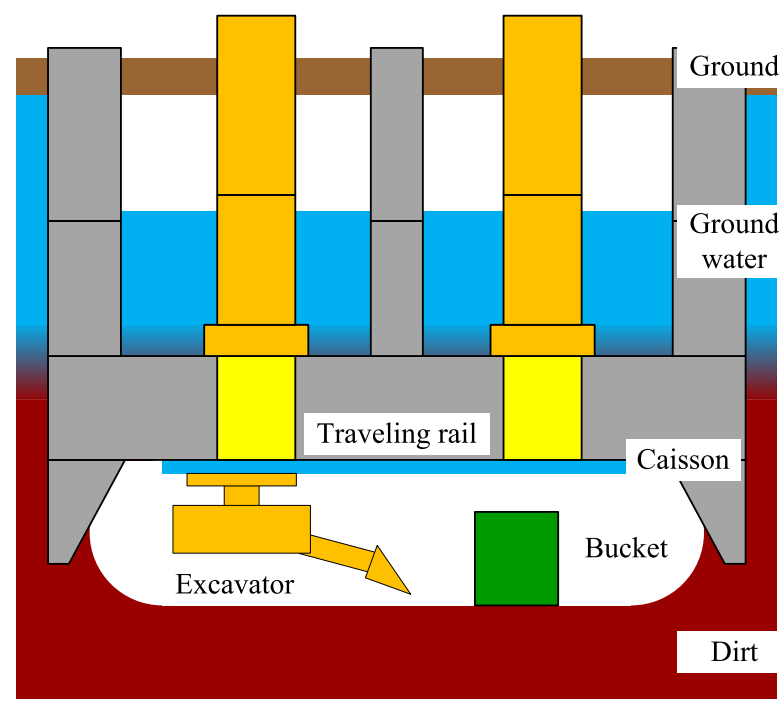

Fig. 1. Outline of pneumatic caisson method Pressurized air is supplied into the working chamber for excavation in order to prevent underground water from coming into the chamber.

the traveling rail. However, due to the movement of the excavator along the traveling rail, there is a threat of a spark which occurs at the contacts. Even a small spark may cause a large-scale fire because the working chamber is under highair pressure environment. Therefore, in order to reduce the risk of the fire which is caused by the spark, an IPT system for the excavator has been proposed. The IPT system transmits power without electrical contact. Thus, there is a no risk to have a spark as long as electric breakdown does not 


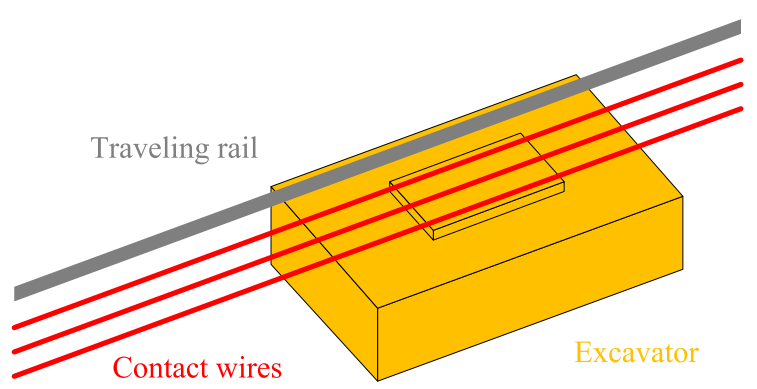

(a) Conventional charging system

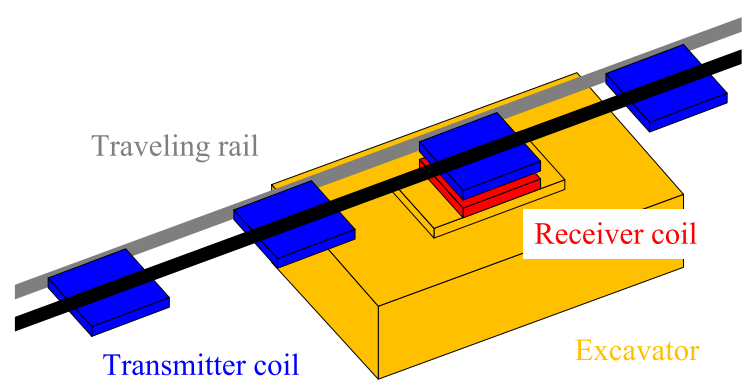

(b) Proposed charging system

Fig. 2. Power supply systems for excavator hanging onto ceiling

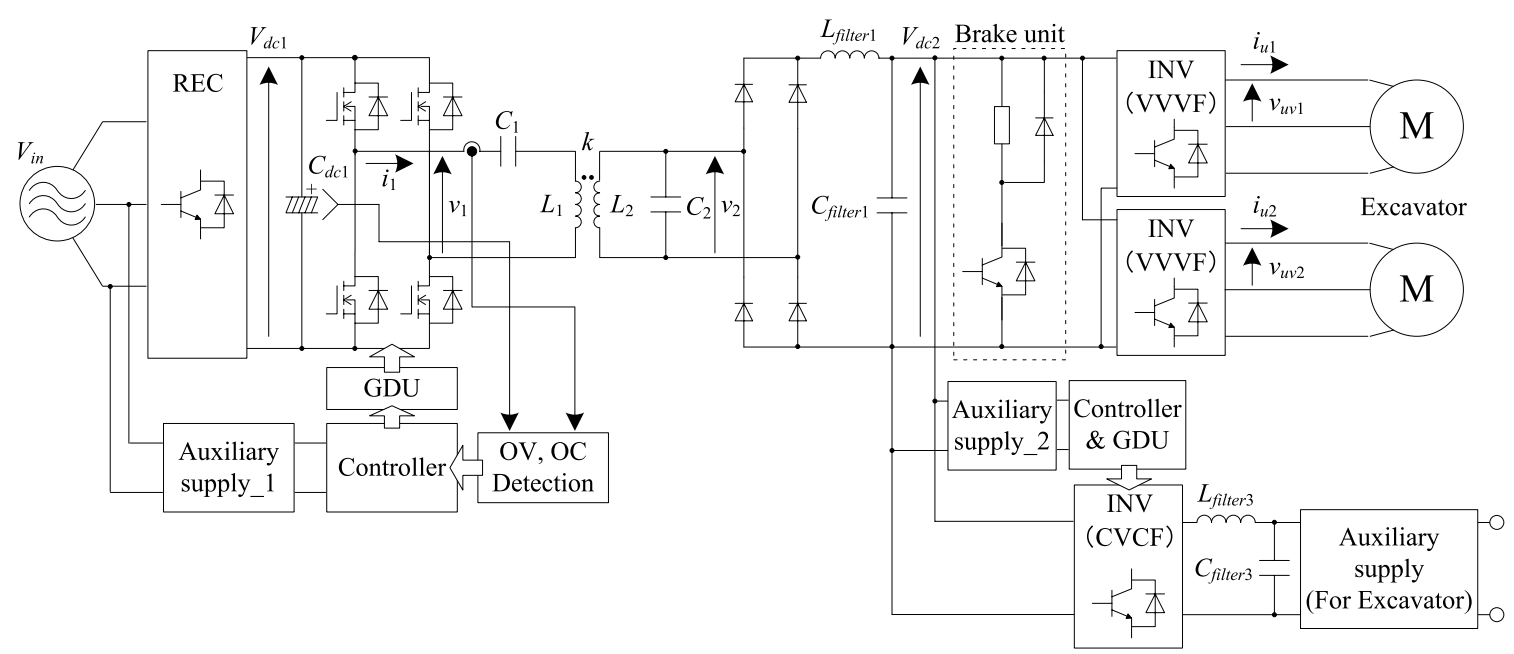

Fig. 3. Inductive power transfer system for excavator

occur. Note that, the breakdown voltage in high-pressurized air environment is higher than the atmosphere according to Paschen's law.

Besides, as the topology of the IPT system, a seriesseries compensation method and a series-parallel compensation methods are well known ${ }^{(2)-(4)}$. In the series-series compensation method, the resonant capacitors are connected into the primary coil and the secondary coil in series. The secondary side behaves a constant-current characteristic by the series-series compensation method when the constant voltage source is used on the primary side ${ }^{(2)-(4)}$.

Therefore, the additional circuits, e.g., the buck converter and the boost converter, on the secondary side are required for the load voltage regulation. In addition, in the seriesseries compensation method, the high-speed communication is needed between the primary side and the secondary side. On the other hand, the series-parallel compensation method, which connects the capacitors to the primary side in series and to the secondary side in parallel provide the constant output voltage characteristic without the additional circuits ${ }^{(5)(6)}$ as long as the winding resistance and parameter error for the resonance can be ignored. However, the parameter error should be considered because inductor and capacitor typically have an error. Moreover, the winding resistance cannot be ignored in such high-power IPT system.

In this paper, the IPT system ${ }^{(7)-(14)}$, which accepts large load fluctuation and resonant parameter error, is developed for the excavator. In the proposed system, the series-parallel compensation is employed in order to cancel out the leakage inductance. Moreover, an output voltage is ideally maintained at constant even under the large load fluctuation without the additional circuit. However, the constant-voltage characteristic degrades due to the winding resistance and the error of the resonant parameter. The output voltage change has to be discussed because the load power dynamically fluctuates in the IPT system for the excavator. Thus, this paper analyzes the output voltage characteristic of the series-parallel compensation method by considering the circuit parameter error and the winding resistances.

The new contribution is providing an analysis how to develop the robust system against the voltage fluctuation in this paper. The analysis takes into account the relationship among the load fluctuation, the resonant parameter and the winding resistance. Based on the analysis on the voltage characteristic, a 15-kW IPT system is developed and tested. The constant load voltage characteristic is evaluated using a resistance and an induction motor load.

\section{Inductive Power Transfer System for Excava- tor}

2.1 System Configuration Figure 3 shows the system configuration of the IPT system for the excavator. The PWM converter as a grid-tied converter and a single-phase inverter are in the primary side. A single-phase rectifier, a brake unit, three-phase variable frequency drive (VFD) inverters and a single-phase constant voltage constant frequency $(\mathrm{CVCF})$ inverter are in the secondary side.

The three-phase VFD inverters, which are operated with the constant voltage per frequency control, are used for adjustable speed drive of induction motors for electric hydraulic 
pumps. The rated synchronous rotational speed of the induction motors are $1800 \mathrm{rpm}$ (at $60 \mathrm{~Hz}$ ). The brake unit is connected at DC side on the secondary side. The IGBT on the brake unit turns on when the secondary side voltage reaches a threshold of the overvoltage detection to decrease the secondary DC voltage for a protection. The brake unit is normally off, however, it will work when the regeneration current comes to the secondary DC side to avoid the breakdown of the secondary circuit. The single-phase CVCF inverter is used as an auxiliary supply, which is needed for the control of the excavator because the existing control circuit of the excavator, which has been operated by AC $400 \mathrm{~V}$, is used. The output voltage of the single-phase CVCF inverter is $400 \mathrm{~V}$ at $60 \mathrm{~Hz}$. The rated power of the CVCF inverter is $1.5 \mathrm{~kW}$.

The power is wirelessly supplied from the primary side and the secondary side. The series-parallel compensation is employed in the system. Therefore, the secondary DC voltage is constant in the ideal conditions because the secondary side output features a constant-voltage characteristic regardless of a load fluctuation when the primary side is driven at constant voltage. However, an error of the resonant parameter and the winding resistance practically degrade the constant-voltage characteristic.

2.2 Compensation Method Figure 4 shows the typical compensation methods, which connects resonance capacitors to the primary side coil and the secondary side coil in series and parallel, respectively, in order to cancel out the reactive power ${ }^{(15)}$. Reactance by leakage inductance are canceled out because of the resonance with the transmission coil. Consequently, the fundamental power factor from the primary side is unity.

Figure 4(a) shows the series-series compensation method, which features a constant current characteristic at the secondary side when the primary side is driven by a constant voltage. Therefore, the series-series compensation is unsuitable for the existing system because the additional circuit is needed in order to convert the constant current characteristic into the constant-voltage characteristic. In addition, the series-series compensation is unsuitable for the existing system because a high-speed communication is needed between the primary side and the secondary side.

On the other hand, Fig. 4(b) shows the series-parallel compensation method, which features a constant voltage characteristic at the secondary side, when the primary side is driven by a constant voltage. When the winding resistance can be ignored, the voltage gain from the input and the output is expressed by

$$
\frac{v_{2}}{v_{1}}=\frac{R_{e q} \omega^{2} L_{m}\left(L_{1}-L_{m}\right)}{\Delta} .
$$

where $R_{e q}$ is the equivalent $\mathrm{AC}$ resistance, $r_{1}$ and $r_{2}$ are the winding resistances, $L_{m}$ is the mutual inductance, and $\Delta$ is

$$
\Delta=\left|\begin{array}{ccc}
r_{1}+j \omega\left(L_{1}-\frac{1}{\omega^{2} C_{1}}\right) & -j \omega L_{m} & 0 \\
-j \omega L_{m} & r_{2}+j \omega\left(L_{2}-\frac{1}{\omega^{2} C_{2}}\right) & j \frac{1}{\omega C_{2}} \\
0 & j \frac{1}{\omega C_{2}} & R_{e q}-j \frac{1}{\omega C_{2}}
\end{array}\right|
$$

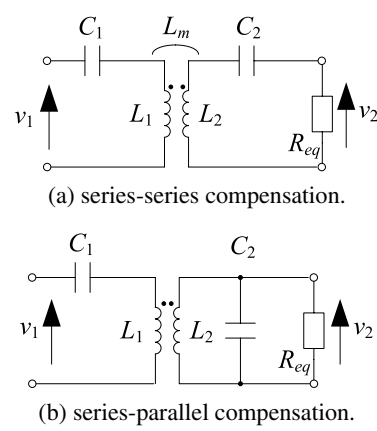

Fig. 4. Typical compensation methods to compensate a leakage inductance due to weak magnetic coupling.

Note that, the derivation of these equations will be shown in the next chapter.

When the winding resistances $r_{1}$ and $r_{2}$ can be ignored, and the resonant conditions are satisfied, Eq. (1) can be simplified into $^{(16)}$

$$
\frac{v_{2}}{v_{1}}=\frac{1}{k} \sqrt{\frac{L_{2}}{L_{1}}} .
$$

It means that the secondary voltage will be constant regardless of the load when the winding resistances can be ignored, and the resonant capacitors $C_{1}$ and $C_{2}$ are in resonant condition. Therefore, the series-parallel compensation is suitable to be applied to the proposed system because the IPT is possible to be applied into the existing excavator system with a smaller number of codifications.

However, the error of the resonant parameter needs to be considered because the resonant capacitors and transmission coils typically have an error as against the ideal value for the resonance. In addition, the winding resistances cannot be ignored in the high-power IPT system because the winding resistance causes a large voltage drop regarding to the output power, which is determined by the operation of hydraulic pump.

\section{Design of Transmission Coils}

3.1 Specifications Figure 5 shows the transmission coils. The primary coil is placed in the upper side. On the other hand, the secondary coil is on the excavator. Besides, in the proposed system, the solenoid coil is employed to obtain higher magnetic coupling in comparison with a circular coil. The cores are PC40 manufactured by TDK. The size of the core is $\mathrm{W} 237 \times \mathrm{H} 210 \times \mathrm{D} 20 \mathrm{~mm}$. Meanwhile, the transmission distance is $50 \mathrm{~mm}$. The transmission distance is determined so that the secondary coil does not contact the primary coil when the excavator moves along the rail.

3.2 Parameter Design Figure 6 shows the equivalent circuit for designing the IPT system. The circuit equations of the equivalent circuit, which is shown Fig. 6 are calculated as

$$
\begin{aligned}
& V_{1}=\left\{r_{1}+j \omega\left(L_{1}-\frac{1}{\omega^{2} C_{1}}\right)\right\} I_{1}-j \omega L_{m} I_{2} \ldots \ldots \\
& 0=-j \omega L_{m} I_{1}+\left\{r_{2}+j \omega\left(L_{2}-\frac{1}{\omega^{2} C_{2}}\right)\right\} I_{2}+j \frac{1}{\omega C_{2}} I_{3}
\end{aligned}
$$




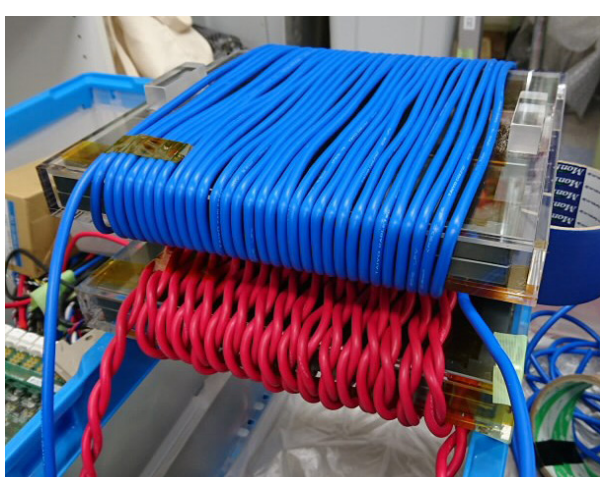

Fig. 5. Transmission coils which is used core with PC40 manufactured by TDK. Upper side is primary coil, lower side is secondary coil. Coil size is W237 $\times \mathrm{H} 210 \times$ D20 $\mathrm{mm}$. Transmission distance is $50 \mathrm{~mm}$

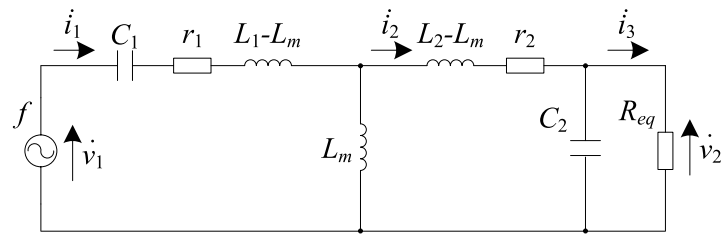

Fig. 6. Equivalent circuit of IPT system with seriesparallel compensation

$$
0=j \frac{1}{\omega C_{2}} I_{2}+\left(R_{e q}-j \frac{1}{\omega C_{2}}\right) I_{3} \ldots \ldots \ldots \ldots \ldots \ldots
$$

where $L_{1}$ is the primary inductance, $L_{2}$ is the secondary inductance, $C_{1}$ is the primary compensation capacitor, $C_{2}$ is the secondary compensation capacitor, $L_{m}$ is the mutual inductance, $V_{1}$ is the primary voltage, $R_{e q}$ is the equivalent load resistance, $r_{1}$ is the equivalent series resistance of the primary winding, $r_{2}$ is the equivalent series resistance of the secondary winding, and $\omega$ is the angular frequency of the power supply.

The currents $I_{1}, I_{2}$ and $I_{3}$ are calculated by (7), (8) and (9) when an input voltage $V_{1}$ is applied into the primary side.

$$
\begin{aligned}
& I_{1}=\frac{V_{1}}{\Delta}\left[\left\{r_{2}+j\left(x_{2}+x_{0}-x_{p}\right)\right\}\left(R_{e q}-j x_{p}\right)+x_{p}^{2}\right] \cdots \cdots \\
& I_{2}=\frac{V_{1}}{\Delta} j x_{0}\left(R_{e q}-j x_{p}\right) \\
& I_{3}=\frac{V_{1}}{\Delta} x_{0} x_{p} \\
& \Delta=\left|\begin{array}{ccc}
r_{1}+j \omega\left(L_{1}-\frac{1}{\omega^{2} C_{1}}\right) & -j \omega L_{m} & 0 \\
-j \omega L_{m} & r_{2}+j \omega\left(L_{2}-\frac{1}{\omega^{2} C_{2}}\right) & j \frac{1}{\omega C_{2}} \\
0 & j \frac{1}{\omega C_{2}} & R_{e q}-j \frac{1}{\omega C_{2}}
\end{array}\right| \\
& \ldots \ldots \ldots \ldots \ldots \ldots(10)
\end{aligned}
$$

In (10), $V_{1}$ is the fundamental component of the output voltage of the inverter.

The parameters of the transmission coil are designed with the equivalent circuit. The resistance $R_{e q}$ indicates that equivalent load resistance of the full-bridge rectifier. Then the equivalent load resistance is given by Ref. (16).

$$
R_{e q}=\frac{\pi^{2}}{8} \frac{V_{d c, 2}^{2}}{P_{2}}
$$

where $P_{2}$ is the output power and $V_{d c, 2}$ is the DC voltage on the secondary side.

The secondary inductance should be designed according to

$$
L_{2}=\frac{R_{e q}}{\omega} \frac{k}{\sqrt{1+k^{2}}}
$$

where $V_{d c, 1}$ is the DC voltage on the primary side and $k$ is the coupling coefficient

Eq. (13) is calculated with (12).

$$
L_{1}=L_{2}\left(\frac{8}{\pi^{2} k} \frac{V_{d c, 1}}{V_{d c, 2}}\right)^{2} \ldots
$$

The compensation capacitors $\mathrm{C}_{1}$ and $\mathrm{C}_{2}$ on the primary side and the secondary side are respectively designed in order to cancel out the reactive power at the input frequency. The value of the compensation capacitors is calculated by (14), (15)

$$
\begin{aligned}
C_{1} & =\frac{1}{\omega^{2} L_{1}\left(1-k^{2}\right)} \cdots \ldots \ldots \ldots \ldots \ldots \ldots \ldots \ldots \ldots \ldots \ldots \ldots \ldots \ldots \ldots \ldots \ldots \ldots \ldots \ldots \ldots \ldots
\end{aligned}
$$

3.3 Influence of Parameter Error and Winding Resistance Figure 7 shows the voltage ratio $v_{2} / v_{1}$ against the error of the resonant parameter including the winding resistance. Figure 7 represents the $v_{2} / v_{1}$ ratio which is calculated by (13) and (10). The vertical axis and the horizontal axis are normalized by the designed value calculated by Eqs. (12)(15). Figures $7(\mathrm{a})$ and (b) show the $v_{2} / v_{1}$ ratio against the error of $L_{1}$ and $C_{1}$ and the error of $L_{2}$ and $C_{2}$ from $80 \%$ to $120 \%$, respectively.

$$
\frac{v_{2}}{v_{1}}=\frac{R_{e q} \omega^{2} L_{m}\left(L_{1}-L_{m}\right)}{\Delta} .
$$

As a result of Fig. 7(a), the $v_{2} / v_{1}$ is sensitive to the secondary inductance $L_{2}$ even when the secondary capacitance $C_{2}$ is maintained at $100 \%$. Meanwhile, the sensitivity of the primary inductance $\mathrm{L}_{1}$ on $v_{2} / v_{1}$ is mitigated when the primary capacitance is maintained at $100 \%$. By considering the parameter change of the inductance, the precise primary capacitance and secondary inductance are required for the constant voltage characteristic on the secondary side.

3.4 Influence of Parameter Error and Winding Resistance The size of the coil is decided based on the desired coupling coefficient and the transmission distance, which is obtained from the coupling coefficient maps ${ }^{(17)}$. The core length is decided larger than the core depth because the coupling coefficient may be smaller than the design value.

\section{Experimental Results}

4.1 Experimental Conditions Table 1 shows the parameters of the prototype. The inductances in Table 1 are the measured value including an error. In this test, a resistance or an induction motor is used as the load.

4.2 Resistance Load Figure 8 shows the operation waveforms of the developed system with the resistance load. Figures 8(a) and (b) show the input and output waveforms of the IPT system at an output power of $5 \mathrm{~kW}$ and $10 \mathrm{~kW}$, respectively. In the figure, the secondary voltage is constant 


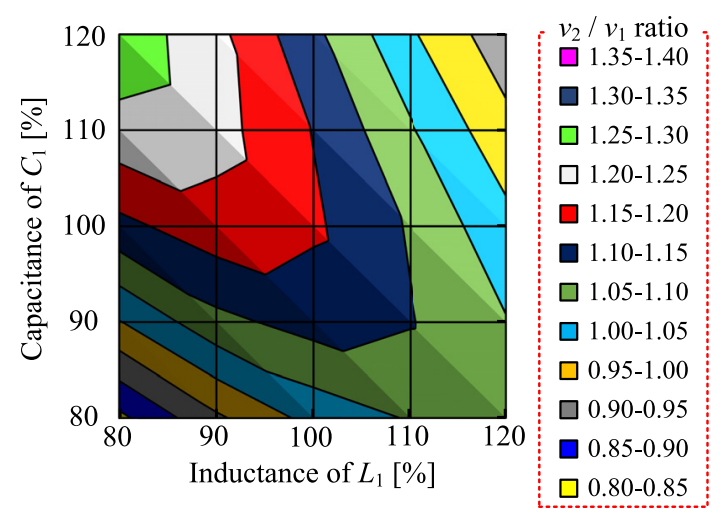

(a) Error of primary inductance $L_{1}$ and primary capacitor $C_{1}$.

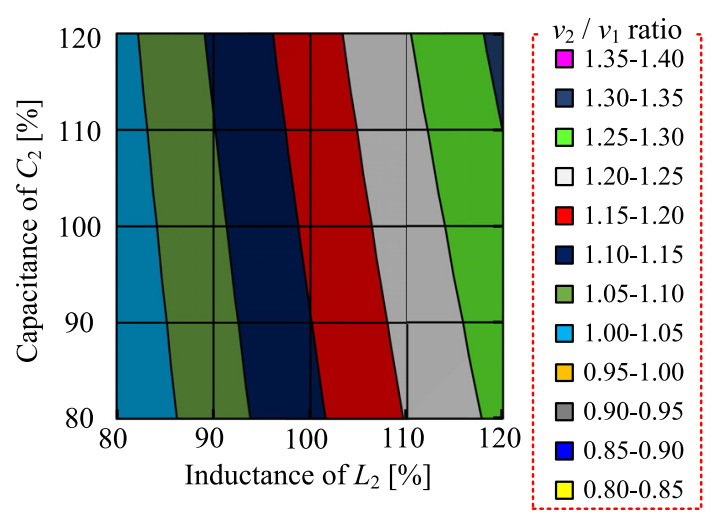

(b) Error of secondary inductance $L_{2}$ and secondary capacitor $C_{2}$.

Fig. 7. $v_{2} / v_{1}$ ratio against error of resonance parameter including winding resistance

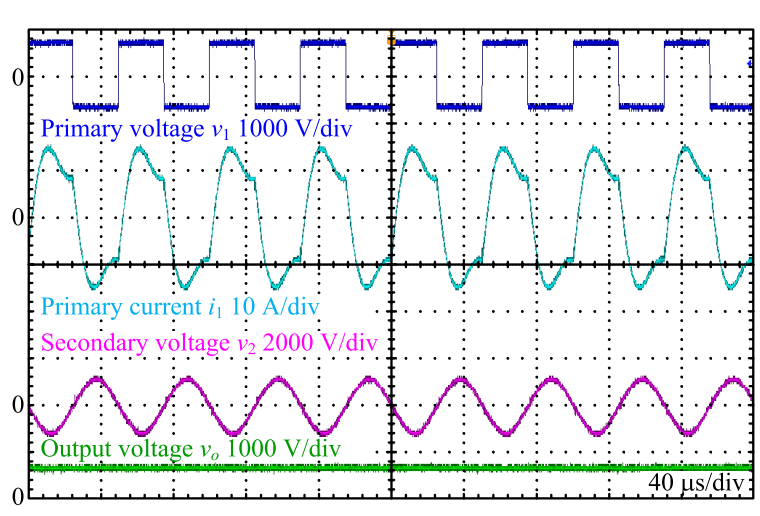

(a) Load of $5 \mathrm{~kW}$.

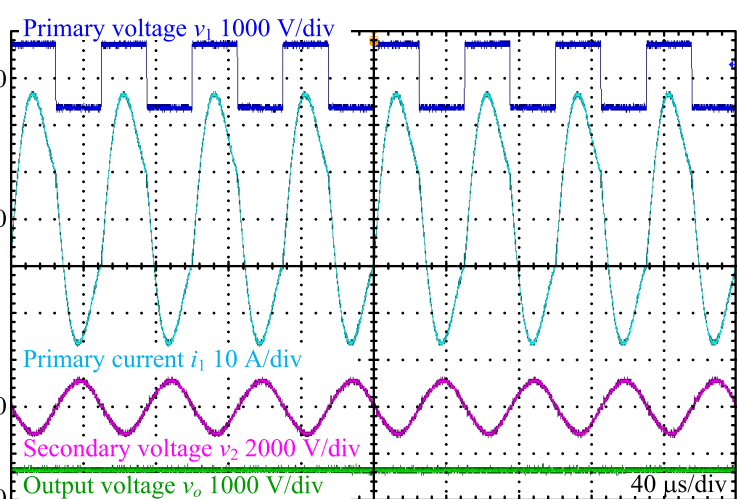

(b) Load of $10 \mathrm{~kW}$.

Fig. 8. Operation waveforms with resistance load

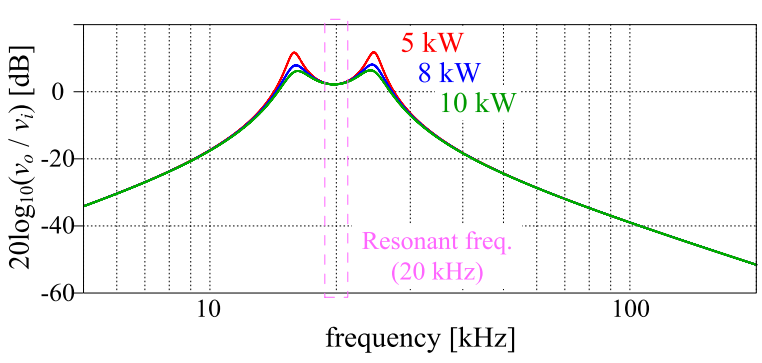

(a) Voltage gain.

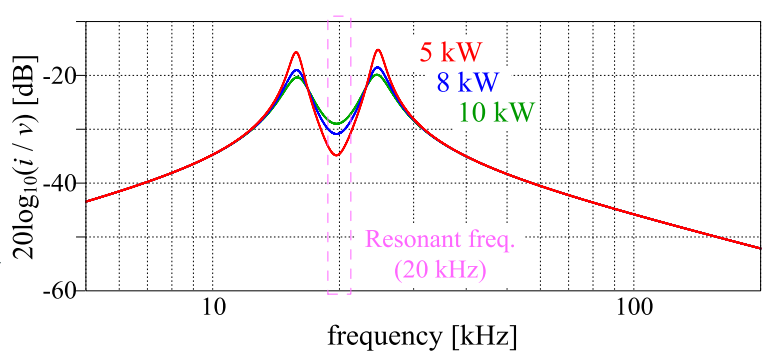

(b) Input admittance.

Fig. 9. Frequency characteristics of input-output voltage and input admittance gain

Table 1. Experimental conditions

\begin{tabular}{lll}
\hline \hline & Symbol & Value \\
\hline Switching frequency & $f$ & $20 \mathrm{kHz}$ \\
Rated power & $P$ & $15 \mathrm{~kW}$ \\
Coupling coefficient & $k$ & 0.41 \\
Primary inductance & $L_{1}$ & $393 \mu \mathrm{H}$ \\
Secondary inductance & $L_{2}$ & $113 \mu \mathrm{H}$ \\
Primary capacitance & $C_{1}$ & $198 \mathrm{nF}$ \\
Secondary capacitance & $C_{2}$ & $582 \mathrm{nF}$ \\
Primary winding resistance & $r_{1}$ & $107 \mathrm{~m} \Omega$ \\
Secondary winding resistance & $r_{2}$ & $70 \mathrm{~m} \Omega$ \\
MOSFETs & BSM120D12P2C005 \\
Diodes & DH 2X61-18A \\
\hline \hline
\end{tabular}

against the load power. Although the resonance condition is adequate, the low-order harmonics affect the primary current in the light load. Thus, the primary voltage and current waveforms are misaligned from the resonance point.

Figure 9 shows the frequency characteristics of the voltage gain. Figure 9(a) is the voltage ratio of the input voltage to the output voltage. Figure 9(b) is the frequency characteristic of the input admittance. The frequency characteristics are obtained by a simulation to evaluate the effect of harmonics components. Around the fundamental frequency of the in Fig. 9(a), the gain is same value regardless of the output power. Meanwhile, the input admittance in Fig. 9(b) at the fundamental frequency depends on the output power in spite of the constant admittance on the low order harmonics frequency. This frequency characteristic cause the large current distortion at light-load region.

Figure 10 shows the frequency characteristics of the input admittance. The admittance of the fundamental component becomes smaller at light load, which has been expected from the frequency characteristics which is shown in Fig.9(b). 


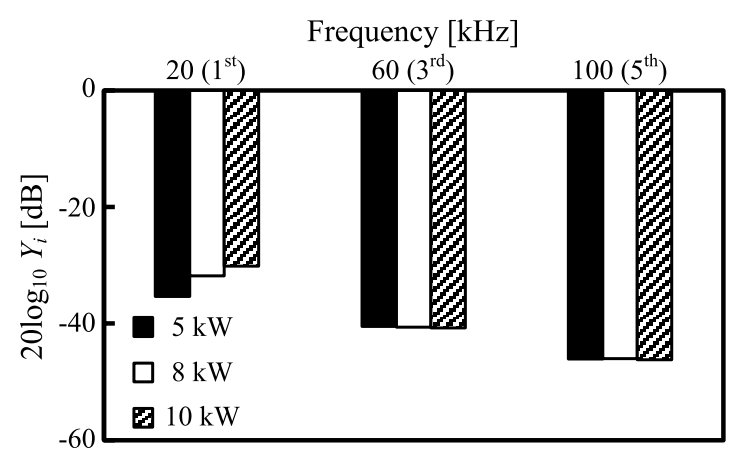

Fig. 10. Frequency characteristics of primary admittance

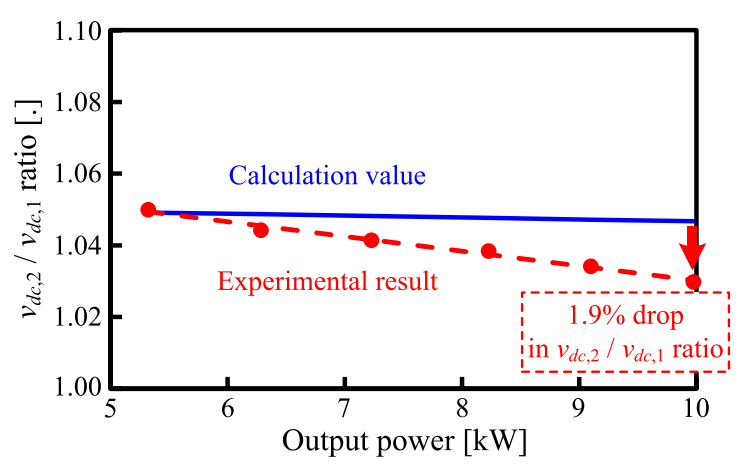

Fig. 11. Voltage ratio between primary side and secondary side

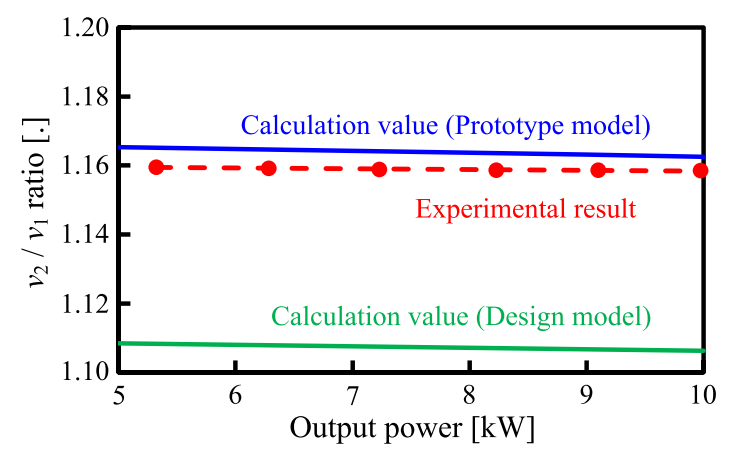

Fig. 12. Voltage gain between the primary voltage and secondary voltage

Therefore, the distortion of the primary current at $5 \mathrm{~kW}$ is larger than the waveforms at $10 \mathrm{~kW}$ because low-order harmonics component of the primary current are constant.

Figure 11 shows the voltage ratio of the primary DC voltage to the secondary DC voltage against the output power. The blue line in Fig. 11 represents the calculation value, which is calculated without a consideration of the resistance components in the rectifier. In the proposed system, the voltage ratio of the secondary and the primary voltage is expected to be constant because the series-parallel compensation is employed in order to cancel out the leakage inductance. However, the voltage ratio of the primary DC voltage to the secondary DC voltage ratio decreases by $1.9 \%$ when the output power increases because the effect of voltage drop which is caused by the winding resistance is large at the high output power.

Figure 12 shows the voltage ratio of the primary to secondary voltage against the output power. The blue line in
Fig. 12 represents the calculation value by (13) and (7) using actual parameters considering the error from a nominal value. The green line in Fig. 12 represents calculation value which is calculated using (13) and (7) with design parameters (theoretical value). The experimental results agree with the calculation value of the prototype model with a small error (less than $0.5 \%)$. The error is caused by the difference between the nominal values and the actual values in the process of the resonant parameter design. Nevertheless, the secondary/primary voltage ratio characteristic is constant regardless of the output power. Therefore, it is confirmed that the decrease in the output/input voltage ratio at the high output power is mainly caused by the post-stage conversion, i.e., the rectifier.

Figure 13 shows the operation waveforms of the transient characteristic with the resistance load. Figures 13(a) and (b) show the step load response from $10 \mathrm{~kW}$ to $5 \mathrm{~kW}$, and vice versa, respectively. The secondary DC voltage is maintained at constant even when the load step occurs. Consequently, it is confirmed that the secondary DC voltage is constant regardless of the output power by using the series-parallel compensation as a leakage inductance canceling method. In particular, the secondary DC voltage is constant even when a large load fluctuation occurs.

4.3 Excavator (Induction Motors) Figure 14 shows the operation waveforms with the induction motor loads, which are connected to the pump. The output power is $15 \mathrm{~kW}$.

Figure 14(a) shows the primary voltage and current waveforms whereas Fig. 14(b) shows the secondary DC voltage, output voltage, and current waveforms. As shown in Fig. 14(a), the fundamental power factor of the inverter output is almost unity. The power is transmitted at $20 \mathrm{kHz}$. Moreover, the primary current is confirmed that the waveform distortion is small because the fundamental components is relatively large, i.e., the influence of low-harmonics components is relatively small. Figure 14(b) shows the output voltage and current of the three-phase inverter. The output frequency of the three-phase inverter is $60 \mathrm{~Hz}$ because the induction motor is drive at a rated speed $1800 \mathrm{rpm}$ with the number of poles of four.

Figure 15 shows the operation waveforms of the transient characteristic in the induction motor load. Figures 15(a) and (b) show the step response from $5 \mathrm{~kW}$ to $15 \mathrm{~kW}$ and vice versa, respectively. Due to the load change, the output current of the proposed IPT system is increased. It means that the output three-phase currents increase because the three-phase inverter is operated with the constant voltage per frequency control at rated speed. The secondary DC voltage is maintained at the constant value even when the load step occurs. The voltage fluctuation owing to the load change is less than $4.3 \%$. Consequently, it is confirmed that the secondary DC voltage is constant regardless of the output power by using the series-parallel compensation. In particular, the secondary DC voltage is constant even when a large load fluctuation occurs.

\section{Conclusion}

In this paper, the inductive power transfer system was applied into the existing excavator in order to reduce the fire risk which is caused by the spark of contact charging system. In the proposed system, the load voltage against the 


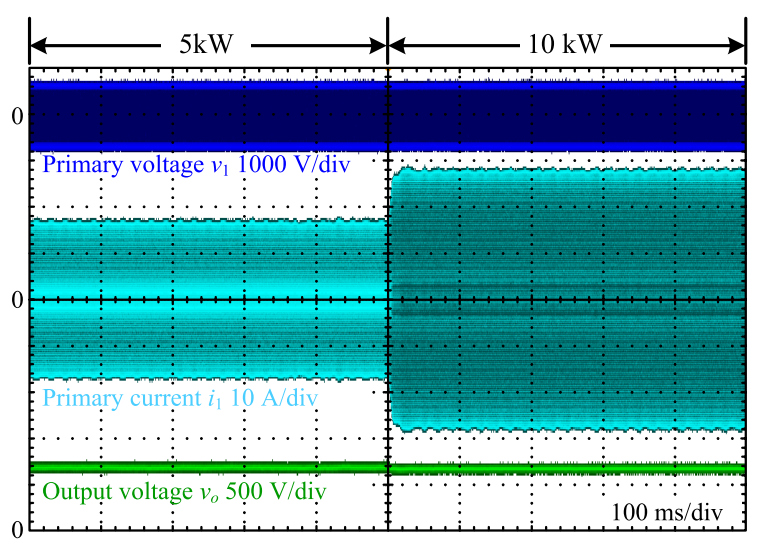

(a) Step load response from $5 \mathrm{~kW}$ to $10 \mathrm{~kW}$.

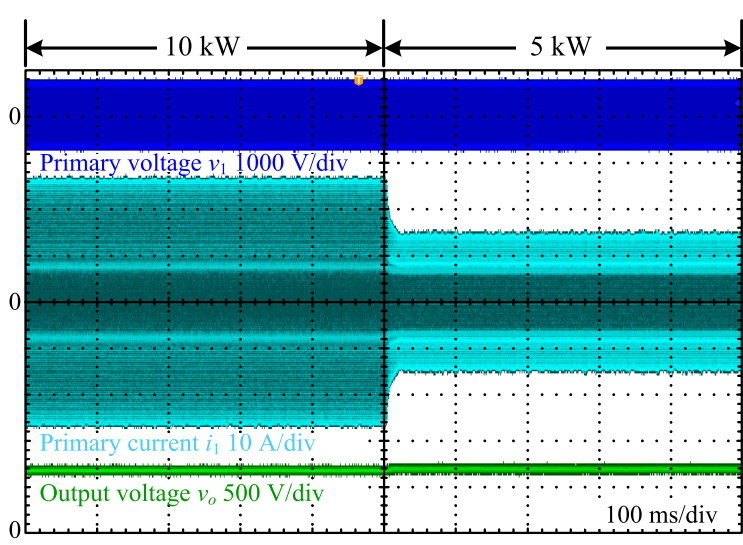

(b) Step load response from $10 \mathrm{~kW}$ to $5 \mathrm{~kW}$.

Fig. 13. Operation waveforms of transient characteristic with resistance load

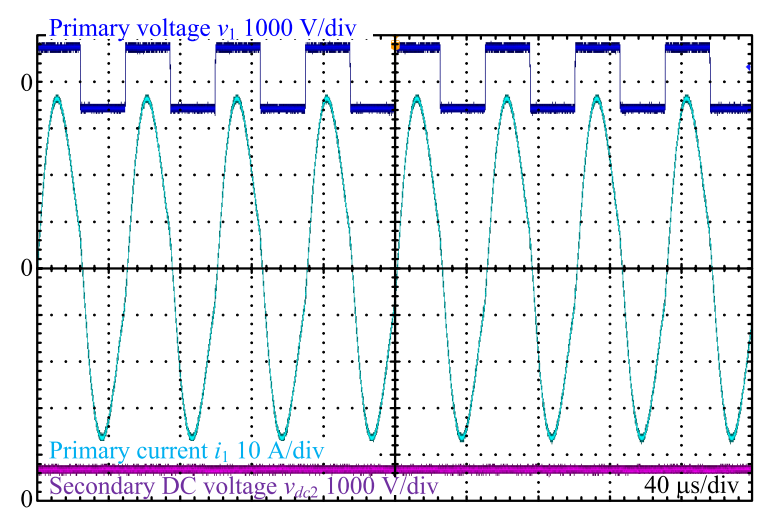

(a) Primary voltage and current waveform.

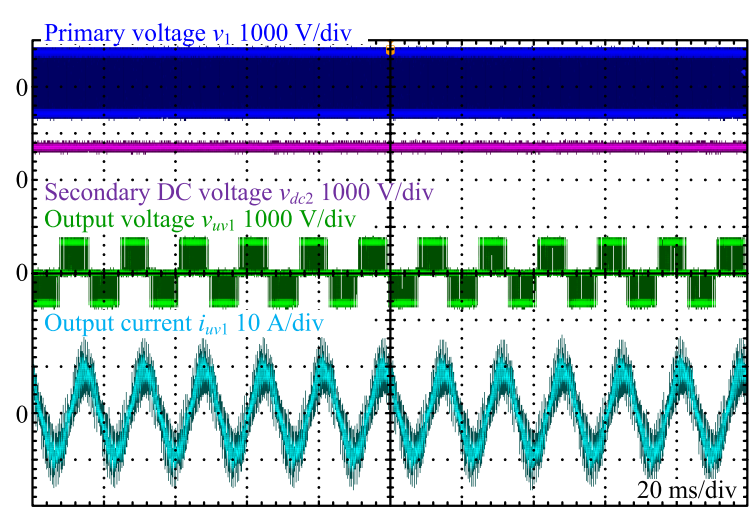

(b) Secondary DC voltage, output voltage and current waveform.

Fig. 14. Operation waveforms with induction motor load

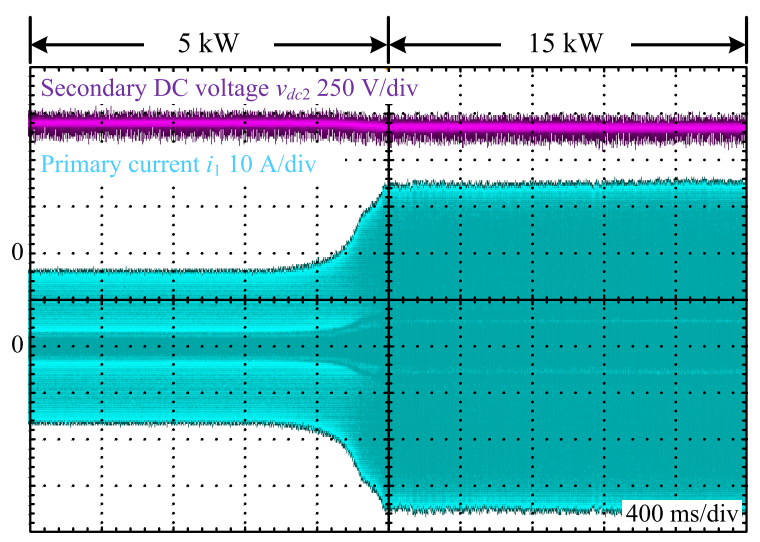

(a) Step load response from $5 \mathrm{~kW}$ to $15 \mathrm{~kW}$.

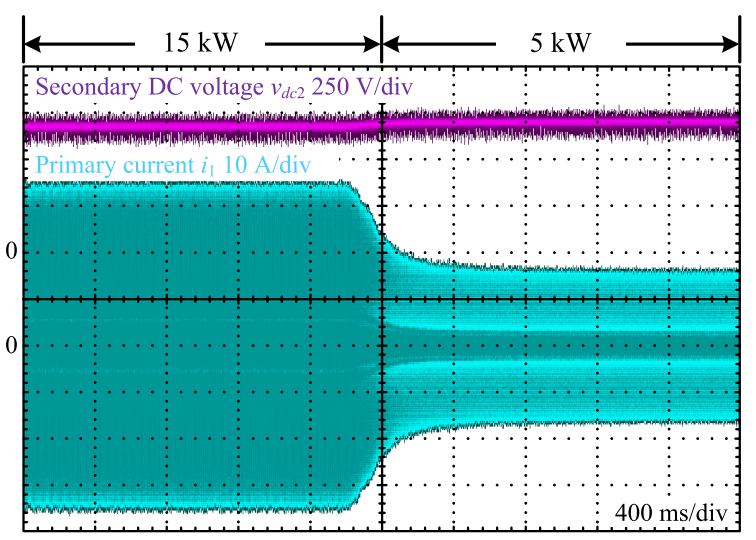

(b) Step load response from $15 \mathrm{~kW}$ to $5 \mathrm{~kW}$.

Fig. 15. Operation waveforms of transient characteristic with induction motor load

load fluctuation should be stabilized without the additional circuit. In order to stabilize the load voltage against the load fluctuation, the series-parallel compensation method has been applied as the method in order to cancel out the leakage inductance. Moreover, the constant-voltage characteristic depending on the error of the resonant parameter and the winding resistance is theoretically analyzed in order to obtain the constant-voltage characteristic. In the experiments with an output power of $15 \mathrm{~kW}$, the voltage fluctuation was smaller than $4.3 \%$. The constant voltage is maintained even when the load step of the induction motor occurs, i.e. from $5 \mathrm{~kW}$ to $15 \mathrm{~kW}$ operation and vice versa. From the experimental results, the constant secondary DC voltage characteristic was confirmed, i.e. the constant output voltage.

\section{References}

( 1 ) K. Kodaki, M. Nakano, and S. Maeda: "Development of the automatic system for pneumatic caisson", ELSEVIER Automation in Construction, Vol.6, No.3, pp.241-255 (1997)

( 2 ) K. Hata, T. Imura, and Y. Hori: "Maximum Efficiency Control of Wireless Power Transfer via Magnetic Resonant Coupling Considering Dynamics of DC-DC Converter for Moving Electric vehicles", IEEE Applied Power Electronics Conference and Exposition, pp.3301-3306 (2015)

( 3 ) M. Kato, T. Imura, and Y. Hori: "Study on Maximize Efficiency by Secondary Side Control Using DC-DC Converter in Wireless Power Transfer via Magnetic Resonant Coupling", The International Electric Vehicle Symposium \& 
Exhibition (2013)

( 4 ) M. Sato, G. Guidi, T. Imura, and H. Fujimoto: "Model for Loss Calculation of Wireless In-Wheel Motor Concept Based on Magnetic Resonant Coupling", IEEE Workshop on Control and Modeling for Power Electronics, No.16267987 (2016)

( 5 ) T. Fujita, Y. Kaneko, and S. Abe: "Contactless Power Transfer Systems using Series and Parallel Resonant Capacitors", IEEJ Trans. of Industry Applications, Vol.127, No.2, pp.174-180 (2007)

( 6 ) R. Ota, N. Hoshi, and J. Haruna: "Design of Compensation Capacitor in S/P Topology of Inductive Power Transfer System with Buck or Boost Converter on Secondary Side", IEEJ Journal of Industry Applications, Vol.4, No.4, pp.476-485 (2015)

( 7 ) K. Kusaka and J. Itoh: "Development Trends of Inductive Power Transfer Systems Utilizing Electromagnetic Induction with Focus on Transmission Frequency and Transmission Power", IEEJ Transactions on Industry Applications, Vol.137, No.5, pp.445-457 (2017)

( 8 ) S. Li and C.C. Mi: "Wireless Power Transfer for Electric Vehicle Applications", IEEE Journal, Vol.3, No.1, pp.4-17 (2015)

( 9 ) D. Shimode, T. Murai, and S. Fujiwara: "A Study of Structure of Inductive Power Transfer Coil for Railway Vehicles", IEEJ Journal of Industry Applications, Vol.4, No.5, pp.550-558 (2015)

(10) T. Mizuno, T. Ueda, S. Yachi, R. Ohtomo, and Y. Goto: "Dependence of Efficiency on Wire Type and Number of Strands of Litz Wire for Wireless Power Transfer of Magnetic Resonant Coupling", IEEJ Journal of Industry Applications, Vol.3, No.1, pp.35-40 (2014)

(11) T. Koyama, K. Umetani, and E. Hiraki: "Design Optimization Method for the Load Impedance to Maximize the Output Power in Dual Transmitting Resonator Wireless Power Transfer System", IEEJ Journal of Industry Applications, Vol.7, No.1, pp.49-55 (2018)

(12) S. Li and C.C. Mi: "Wireless Power Transfer for Electric Vehicle Applications", IEEE Journal, Vol.3, No.1, pp.4-17 (2015)

(13) A. Kurs, A. Karalis, R. Moffatt, J.D. Joannopoulos, P. Fisher, and M. Soljacic: "Wireless Power Transfer via Strongly Coupled Magnetic Resonances", SCIENCE, Vol.317, pp.83-86 (2007)

(14) K. Inoue, K. Kusaka, and J. Itoh: "Reduction in Radiation Noise Level for Inductive Power Transfer Systems using Spread Spectrum Techniques", IEEE Transaction on Power Electronics, Vol.33, No.4, pp.3076-3085 (2018)

(15) T. Imura and Y. Hori: "Unified Theory of Electromagnetic Induction and Magnetic Resonant Coupling", IEEJ Trans. of Industry Applications, Vol.135, No.6, pp.697-710 (2015)

(16) R. Bosshard, J.W. Kolar, J. Muhlethaler, I. Stevanovic, B. Wunsch, and F. Canales: "Modeling and $\eta$ - $\alpha$-Perato Optimization of Inductive Power Transfer Coils for Electric Vehicles", IEEE Transactions, Vol.3, No.1, pp.50-64 (2015)

(17) K. Inoue, K. Kusaka, D. Sato, and J. Itoh: "Coupling Coefficient Maps for Wireless Power Transfer Using Solenoid Type Coil", IEICE Workshop on EE and WPT, No.WPT2016-34, pp.85-90 (2016)

Keisuke Kusaka (Member) received his B.S. and M.S. degrees from

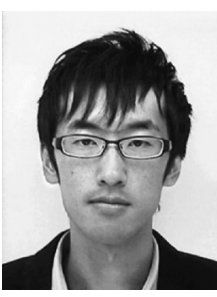
Nagaoka University of Technology, Niigata, Japan in 2011, 2013, respectively. From 2015 to 2016, he was with Swiss Federal Institute of Technology in Lausanne (EPFL), Switzerland as a trainee. In 2016, he received his Ph.D. degree in energy and environment science from Nagaoka University of Technology. From 2016 to 2018, he was with Nagaoka University of Technology as a researcher. He is currently an assistant professor at Nagaoka University of Technology. His current research interests include an inductive power transfer system and high-frequency converters. He received the second prize paper award in IPEC-Niigata 2018.
Kent Inoue (Non-member) was born in Ibaraki, Japan, in 1993. He

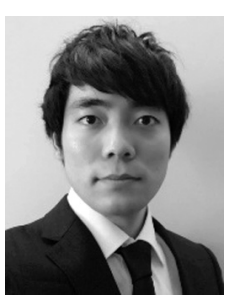
received his B.S. and M.S. degrees in electrical, electronics and information engineering from Nagaoka University of Technology, Niigata, Japan in 2016 and 2018, respectively. Since 2018, he has been with DENSO Corporation, Aichi, Japan. His current research interests includes an inductive power transfer system.

Jun-ichi Itoh (Senior Member) was born in Tokyo, Japan, in 1972. He

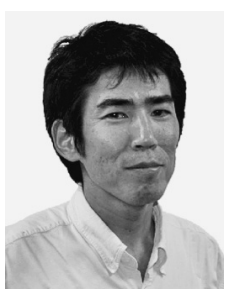
received his M.S. and Ph.D. degree in electrical and electronic systems engineering from Nagaoka University of Technology, Niigata, Japan in 1996, 2000, respectively. From 1996 to 2004, he was with Fuji Electric Corporate Research and Development Ltd., Tokyo, Japan. He was with Nagaoka University of Technology, Niigata, Japan as an associate professor. Since 2017, he has been a professor. His research interests are matrix converters, $\mathrm{dc} / \mathrm{dc}$ converters, power factor correction techniques, energy storage system and adjustable speed drive systems. He received IEEJ Academic Promotion Award (IEEJ Technical Development Award) in 2007. In addition, he also received Isao Takahashi Power Electronics Award in IPEC-Sapporo 2010 from IEEJ, 58th OHM Technology Award from The Foundation for Electrical Science and Engineering, November, 2011, Intelligent Cosmos Award from Intelligent Cosmos Foundation for the Promotion of Science, May, 2012, and Third prize award from Energy Conversion Congress and Exposition-Asia, June, 2013. Prizes for Science and Technology (Development Category) from the Commendation for Science and Technology by the Minister of Education, Culture, Sports, Science and Technology, April 2017. Dr. Itoh is a senior member of the Institute of Electrical Engineers of Japan, the Society of Automotive Engineers of Japan and the IEEE. 